\title{
Management of hypertension in children and adolescents
}

\author{
P. De Bruyne ${ }^{1}$, J. Vande Walle ${ }^{2}$
}

${ }^{1}$ Department of Pediatrics, ${ }^{2}$ Department of Pediatric Nephrology, Ghent University Hospital, Ghent, Belgium

Hypertension has been recognized as an important health issue in the pediatric population over the past years. This emphasizes the need for an organized and effective plan for diagnosis and management. This review provides information to guide physicians through a structured approach to (1) screen children for hypertension during routine visits; (2) use normative blood pressure tables for diagnosis and classification; (3) perform a clinical evaluation to identify the presence of risk factors, comorbidities and/or target organ damage; and (4) initiate an individualized plan of care that includes follow-up blood pressure measurement, therapeutic lifestyle changes and - if necessary - pharmacological therapies.

Keywords: Hypertension, Children, Adolescents, Blood pressure, Treatment

\section{Introduction and Purpose}

There is growing evidence that mild blood pressure (BP) elevations in children and adolescents are much more common than it was thought before. ${ }^{1}$ Recent reports indicate that hypertension now affects between 3 and $5 \%$ of the pediatric population. ${ }^{2}$ This makes hypertension one of the most common chronic diseases of childhood, especially in adolescence. ${ }^{3}$ Longitudinal studies have made it clear that BP abnormalities during childhood do translate into adult hypertension. ${ }^{1-6}$ Where there was in the past a predominance of secondary hypertension in children, associated with renal disorders and/or drug therapy, there is now an increasing frequency of essential hypertension.

There are two major reference frames for the management of hypertension in children: The Fourth Report on the Diagnosis, Evaluation, and Treatment of High Blood Pressure in Children and Adolescents from the National Heart, Lung and Blood Institute ${ }^{6}$ and the revised guidelines of the European Society of Hypertension. ${ }^{1}$ It should be noted that these pediatric guidelines are much more expert than evidence based, since they are supported by only few observational and interventional trials in contrast with the adult guidelines. ${ }^{1}$ The remoteness of incident cardiovascular events from BP values many years beforehand makes the relationship of BP values with events hardly feasible. Consequently, many of the classifications and recommendations in children are based on

Correspondence to: Dr Pauline De Bruyne, Department of Pediatrics, Ghent University Hospital, Ghent, Belgium. Email: pauline.debruyne@ uzgent.be statistical considerations, and result from assumptions rather than the results of experiments or result from extrapolations from evidence obtained in adults. 1

Increased BP at pediatric age is an underestimated problem in primary and secondary care in Belgium. Major attention to this topic is only given in specialized pediatric nephrology and cardiology journals. Therefore there is a need to translate these international guidelines into a Belgian setting.

\section{Definition and Classification of Hypertension}

Diagnostic criteria for elevated BP in children are based on the concept that BP in children increases with age and body size, making it impossible to utilize a single BP level to define hypertension, as done in adults. ${ }^{1}$ The definition of elevated BP for children is based on percentiles derived from population studies of healthy children. Extensive pediatric normative data on auscultatory clinic measurements have been provided for the United States, based on more than 70000 children, from the Task Force for Blood Pressure in Children. ${ }^{5-7}$ A few national studies were undertaken in Europe, but were unable to overrule the Task Force for Blood Pressure ${ }^{1}$ as reference, even for the European setting, ${ }^{8}$ since they included less patients, and differences were only mild and therefore hardly clinically relevant.

Normal BP in children is defined as systolic blood pressure (SBP) and diastolic blood pressure (DBP) less than 90th percentile for age, sex and height, whereas hypertension is defined as SBP and/or DBP persistently 95 th percentile or more, measured on at least three separate occasions with the auscultatory 
method. Children with average SBP or DBP 90th percentile or more but less than 95th percentile are classified as having high-normal blood pressure. Adolescents with BP $120 / 80 \mathrm{mmHg}$ or more even if less than 90th percentile are also considered as having high-normal BP. ${ }^{1,6}$ Redwine et al. showed that having high-normal $\mathrm{BP}$ is a higher risk of developing hypertension. ${ }^{2,3}$ Additionally, the Fourth Report provides criteria for staging the severity of hypertension in children and adolescents in stage 1 hypertension and stage 2 hypertension, which can be used clinically to guide evaluation and management. ${ }^{1,3,6}$ Children with stage 2 hypertension should be evaluated and treated more quickly and/or intensively than those with a lower degree of BP elevation (Table 1). ${ }^{1}$

\section{Diagnostic Evaluation \\ Blood pressure measurement}

Patients with hypertension may show symptoms such as headache, malaise, nose bleeding and palpitations but hypertension is predominantly an asymptomatic condition, which can only be diagnosed by routine measurement of BP. ${ }^{3}$ Children above three years of age who are seen in a medical setting should have their BP measured. ${ }^{3,6,9}$ Younger children should have their BP measured in special circumstances: history of prematurity, congenital heart disease, known renal disease or urologic malformations, malignancy, solidorgan transplant, other systemic illnesses and drugs known to be associated with elevated $\mathrm{BP}^{6}{ }^{6}$ The diagnosis of hypertension should be based on multiple office BP measurements, taken on separate occasions over a period. ${ }^{1}$ Although office BP should be used as reference, $\mathrm{BP}$ values obtained out of office may improve the evaluation in untreated and treated individuals. ${ }^{1}$

\section{Office or clinic blood pressure}

Office BP measurement has provided the basis for the present knowledge of the potential risk associated with hypertension and has guided management for many years. ${ }^{1}$ The available reference values for defining BP classes have been obtained by the auscultatory method (Korotkoff sounds-based measurement). ${ }^{1}$ These BP standards, including the 50th, 90th, 95th and 99th percentiles by gender, age, and height are publicly accessible on http://www.nhlbi. nih.gov/guidelines/hypertension/child_tbl.pdf. ${ }^{6}$ Oscillometric devices, which do not measure SBP and DBP directly but calculate BP from pressure oscillations detected in the arm cuff, have been introduced more recently. ${ }^{1,2}$ It should be noticed that values obtained by the oscillometric method are generally higher than values obtained by the auscultatory method. Few oscillometric devices have been successfully validated using an established protocol. The continuously updated data available on monitor validation for children is found at www.dableducational.org. ${ }^{1}$ Another important issue to consider in the measurement of BP in children, is that appropriate cuff size can vary substantially among children of the same age. The cuff bladder should have a width that covers approximately two-thirds of the upper arm and a length that encircles at least $80 \%$ of the upper arm, preferably $100 \%{ }^{6}$ Preferably, BP is measured at the right arm, after the patient has been sitting for 5 minutes, feet on the floor and right arm supported with cubital fossa at heart level. ${ }^{6}$ The right arm is preferred in repeated measures of blood pressure for consistency and comparison with standard tables and because of the possibility of coarctation of the aorta, which might lead to false (low)

Table 1 Classification of hypertension in children and adolescents ${ }^{6}$

\begin{tabular}{|c|c|c|}
\hline & $\begin{array}{l}\text { Systolic or diastolic } \\
\text { blood pressure (if } \\
\text { systolic and diastolic } \\
\text { categories are different, } \\
\text { categorize by the } \\
\text { higher value) }\end{array}$ & $\begin{array}{l}\text { Frequency of BP } \\
\text { measurement }\end{array}$ \\
\hline Normal & $<90$ th & $\begin{array}{l}\text { Recheck at next scheduled } \\
\text { physical examination }\end{array}$ \\
\hline High-normal blood pressure & $\begin{array}{l}\text { 90th to 95th or if BP } \\
\text { exceeds } 120 / 80 \mathrm{mmHg} \\
\text { even if }<90 \text { th percentile }\end{array}$ & Recheck in 6 months \\
\hline Stage 1 hypertension & $\begin{array}{l}\text { 95th-99th percentile } \\
\text { plus } 5 \mathrm{mmHg}\end{array}$ & $\begin{array}{l}\text { Recheck in } 1-2 \text { weeks or } \\
\text { sooner if symptomatic; if } \\
\text { persistently elevated on } \\
\text { two additional occasions, } \\
\text { evaluate or refer to a pediatric } \\
\text { nephrologist/cardiologist } \\
\text { within } 1 \text { month }\end{array}$ \\
\hline Stage 2 hypertension & $\begin{array}{l}>99 \text { th percentile plus } \\
5 \mathrm{mmHg}\end{array}$ & $\begin{array}{l}\text { Evaluate or refer to a pediatric } \\
\text { nephrologist/cardiologist within } \\
1 \text { week or immediately if the } \\
\text { patient is symptomatic }\end{array}$ \\
\hline
\end{tabular}


readings in the left arm. ${ }^{6}$ Moreover, a four extremities BP check is mandatory in a child with hypertension to evaluate for coarctation of the aorta, which is one of the causes of secondary hypertension. ${ }^{10}$ If the leg BP is lower than the arm BP (in supine position), ${ }^{11}$ or if femoral pulses are week or absent, coarctation of the aorta may be present. ${ }^{6}$

\section{Ambulatory blood pressure}

Although office BP is still the reference for the diagnosis of hypertension, ambulatory BP measurement (ABPM) is now increasingly recognized as being indispensable to the diagnosis and management of hypertension, in children of 5 years or older. ${ }^{6,9,12}$ It has contributed significantly to 'unmask' BP phenomena, unlikely to be identified by office BP. ${ }^{1,6}$ These have included the dipping and non-dipping patterns of nocturnal BP, BP values in the hypertensive range in the office but not out-of-office (whitecoat hypertension $)^{1,3,12}$ or, vice versa, in the normotensive range in the office but not out-of-office (masked hypertension). ${ }^{1,12}$ Reference values provided by the German Working Group on Pediatric Hypertension are currently considered the best available data for pediatric ABPM. ${ }^{13,14}$ ABPM is often used in randomized clinical trials of BP-lowering drugs (in adults) to compare antihypertensive efficacy between therapeutic agents and to assess 24-hour BP control, including improvement in nocturnal dipping with treatment. Use of ABPM, therefore, provides additional information on circadian BP control that may alter selection and dosage of an antihypertensive medication. $^{12}$

\section{Home blood pressure}

Concerning home BP measurements, evidence in children and adolescents is limited. In children, home $\mathrm{BP}$ has superior reproducibility than office BP has and is similar to that for ABPM. Home monitoring for 6-7 days with duplicate morning and evening measurements is recommended. Home BP in children is lower than daytime ambulatory PB, probably due to a high level of physical activity during the day. ${ }^{1}$

\section{Evaluation for risk factors and for secondary hypertension}

In order to identify possible causes of hypertension, the first investigations in the child with hypertension should include: a complete (family) history, physical examination, blood exam, urinalysis and ultrasound of kidney and heart. ${ }^{1}$

Primary hypertension often clusters with other risk factors. ${ }^{6}$ Considerable advances have been made in recent years in identifying conditions often associated with and considered responsible for high BP in children and adolescents. ${ }^{1}$ Overweight is probably the most important of the conditions associated with elevated BP in childhood ${ }^{1,4}$ and accounts for more than half of the risk for developing hypertension. ${ }^{1}$ Birth size and postnatal growth have also been recently implicated in the development of high BP and adult cardiovascular disease. ${ }^{1}$ Furthermore, dietary habits early in life, and particularly high salt intake, ${ }^{15}$ have been implicated as factors favoring higher BP values. ${ }^{14}$ Studies on racial differences showed that African-American children had a higher prevalence of overweight/obesity and left ventricle hypertrophy (LVH) than non-African-American children. ${ }^{4,7}$ Sleep disorders including sleep apnea are associated with hypertension, coronary disease, heart failure and stroke in adults. Although limited data are available, they suggest an association of sleepdisordered breathing and higher BP in children. ${ }^{6}$ Consideration of these associated risk factors and appropriate evaluation in those children in whom the hypertension is verified, are important in planning and implementing therapies.

Sustained hypertension in children and adolescents is classified as secondary when a specific cause can be found, which can sometimes be corrected with specific intervention. ${ }^{1}$ The most common causes of secondary hypertension differ according to the age of the children. ${ }^{16}$ In very young children ( $<6$ years), hypertension is most often the result of renal parenchymal diseases such as glomerulonephritis, renal scarring, polycystic kidney, renal artery stenosis and renal dysplasia. ${ }^{1,5}$ Hypertension is present in approximately $50 \%$ of children with chronic kidney disease. ${ }^{17}$ Both high BP and increased proteinuria are predictors of the progression of renal disease among children with chronic kidney disease. ${ }^{17}$ The most common cardiovascular cause of hypertension is coarctation of the aorta and Turner's syndrome. In all ages, following rare but identifiable causes of hypertension should be considered: endocrine diseases (hyperthyroidism, Cushing's syndrome, primary hyperaldosteronism) and some endocrine tumors (pheochromocytoma and neuroblastoma), and food or drugs that raise BP (liquorice, oral contraceptives, steroids, non-steroidal anti-inflammatory drugs, cyclosporin). ${ }^{16}$

\section{Evaluation of target-organ damage}

Once hypertension is confirmed, organ damage evaluation should include heart, great vessels and kidney, due to the importance of subclinical organ damage as an intermediate stage in the continuum of vascular disease. ${ }^{1,3}$ Subsequently, evaluation of organ damage is also useful as an intermediate endpoint for monitoring treatment protection. ${ }^{1}$ Neurologic and ophthalmologic clinical evaluation are indicated in severe hypertension. ${ }^{1}$ The most useful and relevant way (and primary tool) to evaluate target-organ damage is by assessing left ventricular mass using echocardiography. ${ }^{3,5,6,9,16}$ Left ventricular hypertrophy 
can result from prolonged exposure of the left ventricle to increased afterload caused by increased systemic BP. ${ }^{3}$ The prevalence of $\mathrm{LVH}$ in children and adolescents with arterial hypertension has been found to be around $20-41 \% .{ }^{18}$ Identification of LVH may suggest the need for more urgent and more aggressive treatment of hypertension. ${ }^{3,5}$

\section{Antihypertensive Treatment When to initiate antihypertensive treatment}

As in adults, also in children, the decision to initiate antihypertensive treatment should not be taken on BP levels alone, but should consider the presence or absence of target organ damage, other (cardiovascular) risk factors or diseases such as obesity, renal diseases or diabetes. ${ }^{1}$ It should be stressed that if the patient is symptomatic, immediate referral and treatment are indicated. ${ }^{19}$ In children with proven secondary hypertension, specific treatment of the underlying disease must be initiated immediately after detection. ${ }^{1}$ In children with primary hypertension, antihypertensive therapy should first target the risk factors for BP elevation (i.e. overweight, increased salt intake, low physical activity). ${ }^{1}$

\section{Goal of Treatment}

\section{Blood pressure target in the general hypertensive population}

Pediatric BP targets are commonly defined population based, in the absence of prospective long-term studies linking children BP levels to cardiovascular outcomes. The 95 th percentile is commonly used as a cutoff for defining hypertension in children and adolescents without renal comorbidity. The recommendations of the European Society of Hypertension state that this provides a rationale for targeting children and adolescents with primary hypertension to a BP below the 95th but also mention that is probably wiser and safer to aim at a BP below the 90th percentile. ${ }^{1}$

\section{Blood pressure target in renal disease}

The international guidelines advocate to target a BP $<50$ th percentile in hypertension associated with renal disease. This statement is to some extent supported by the prospective randomized ESCAPE trial $^{17}$ : strict BP control aiming for a 24-h target below the 50th percentile of mean arterial pressure by the addition of other antihypertensive agents to angiotensin converting enzyme inhibitor (ACEI) therapy resulted in a better 5-year renal survival, despite a return of proteinuria toward pretreatment values. Analysis by achieved BP levels showed similar renal outcomes with any 24-h BP below the 75th percentile, contrasting with significantly reduced 5year renal survival in patients exceeding the cutoff level. Proteinuria appears to be an important modifier of the renoprotective efficacy of intensified
BP control. Admittedly, only a minority of patients in the different studies reached values $<50$ percentile. ${ }^{1}$

\section{Therapeutic Strategies \\ Life style changes}

Non-pharmacological treatment of hypertension includes weight loss, aerobic exercise, restriction of salt intake and stress reduction. ${ }^{5}$ While these therapies may be effective in reducing the BP to the targeted levels, pharmacologic therapy will need to be considered if they do not. ${ }^{5}$ Life style changes should not only precede but also accompany pharmacological treatment. ${ }^{1}$

\section{Therapeutic therapy}

Therapeutic orphans

A major issue related to the use of antihypertensive medications in young people is the availability of safety and efficacy data. ${ }^{3}$ Historically, few drug trials were conducted in children, with the consequence that many drugs had to be used empirically, without the benefit of specific pediatric efficacy, safety, or dosing information. ${ }^{3}$ Besides, there is lack of suspensions or other age appropriate drug formulations. ${ }^{20}$ In 2007, the European authorities implemented the European Regulation after realizing that children also have the right to be treated with drugs that have been studied in children. ${ }^{1}$ The goal of this Regulation of medicinal products for pediatric use is to increase the availability of medicines authorized for children, as well as to improve the information on the use of medicinal products in the pediatric population. ${ }^{1}$ The Pediatric Regulation requires manufacturers to study medications in children to be able to market them in Europe. Despite this initiative, reliable pediatric data obtained from controlled studies with older compounds with expired patent protection are still not available. ${ }^{1,6}$ Hopefully, the Pediatric Use Marketing Authorization will help resolve this problem, at least in part. ${ }^{1}$ For the time being, the present recommendations on pharmacotherapy in hypertension are based on few industrysponsored studies, and mostly on single-center case series, collective clinical experience, expert opinion and extrapolation from data obtained in adults. ${ }^{1}$

Like in adults, choice of antihypertensive agents can include ACEIs, angiotensin receptor antagonists, calcium antagonists, beta-blockers and diuretics (Table 2). ${ }^{1,5,6}$ Although many individual antihypertensive compounds have been studied in the pediatric age group, no pediatric studies comparing different agents have been conducted. ${ }^{3,5,6,21}$ This situation leaves the prescriber without evidence-based guidance for choice of drug. ${ }^{3,5}$ The etiology of the hypertension, the anticipated benefits for the child, and the potential adverse effects should guide the choice of medication. ${ }^{5}$ Certain co-morbidities that favor certain classes of drugs include the use of an ACEI or angiotensin-II 
receptor blocker $(\mathrm{ARB})$ in patients with diabetes and microalbuminiuria or proteinuric renal disease. Calcium channel blockers are also a good option in patients with diabetes or metabolic syndrome because they improve insulin sensitivity. Beta-blockers and calcium channel blockers should be considered in patients with migraine. In general, black children and adolescents do not respond well to ACEIs at standard doses. Severe symptomatic hypertension should be treated with intravenous antihypertensive drugs. ${ }^{6}$

\section{Monotherapy versus combination therapy}

It is reasonable that in children, treatment should be started with a single drug administered at a low dose in order to avoid rapid fall in BP. If BP does not decrease sufficiently after a few weeks, usually four to eight weeks, an increase to the full dose should be initiated. Once the highest recommended dose is reached, or if the child experiences side effects from the drug when increasing the dose, a second drug from a different class should be added. ${ }^{1}$

Table 2 Recommended initial doses adapted from Lurbe et al., ${ }^{1}$ Kavey et al., ${ }^{3}$ and Flynn and Daniels. ${ }^{20}$ The maximum $^{2}$ recommended dose should not be exceeded.

\begin{tabular}{|c|c|c|c|c|c|c|}
\hline Class & Drug & $\begin{array}{l}\text { Starting oral } \\
\text { dose }\end{array}$ & Interval & $\begin{array}{l}\text { Maximum } \\
\text { daily oral } \\
\text { dose }\end{array}$ & $\begin{array}{l}\text { Labeling for } \\
\text { hypertension } \\
\text { in children } \\
\text { with dosing } \\
\text { advise in } \\
\text { Belgium }\end{array}$ & $\begin{array}{l}\text { Availability of } \\
\text { pediatric } \\
\text { formulation } \\
\text { in Belgium }^{27}\end{array}$ \\
\hline \multirow[t]{4}{*}{ Diuretics } & Chlorthalidone $^{\circ}$ & $0.3 \mathrm{mg} / \mathrm{kg} / \mathrm{day}$ & Once daily & $\begin{array}{l}2 \mathrm{mg} / \mathrm{kg} \\
\text { up to } 50 \mathrm{mg}\end{array}$ & Yes & No \\
\hline & Furosemide & $\begin{array}{l}0.5- \\
2 \mathrm{mg} / \mathrm{kg} / \mathrm{dose}\end{array}$ & $\begin{array}{l}\text { Once to } \\
\text { twice daily }\end{array}$ & $6 \mathrm{mg} / \mathrm{kg}$ & Yes & No \\
\hline & Hydrochlorothiazide & $\begin{array}{l}\text { Not available in } \\
\text { Belgium }\end{array}$ & & & & \\
\hline & Spironolactone & $1 \mathrm{mg} / \mathrm{kg} / \mathrm{day}$ & $\begin{array}{l}\text { Once to } \\
\text { twice daily }\end{array}$ & $\begin{array}{l}3.3 \mathrm{mg} / \mathrm{kg} \\
\text { up to } 100 \mathrm{mg}\end{array}$ & Yes & No \\
\hline \multirow{3}{*}{$\begin{array}{l}\text { Beta- } \\
\text { adrenergic } \\
\text { blockers }\end{array}$} & Atenolol & $\begin{array}{l}0.5- \\
1 \mathrm{mg} / \mathrm{kg} / \mathrm{day}\end{array}$ & $\begin{array}{l}\text { Once to } \\
\text { twice daily }\end{array}$ & $\begin{array}{l}2 \mathrm{mg} / \mathrm{kg} \\
\text { up to } 100 \mathrm{mg}\end{array}$ & No & No \\
\hline & Metoprolol & $1-2 \mathrm{mg} / \mathrm{kg} / \mathrm{day}$ & Twice daily & $\begin{array}{l}6 \mathrm{mg} / \mathrm{kg} \\
\text { up to } 200 \mathrm{mg}\end{array}$ & $>6$ y & No \\
\hline & Propanolol & $1 \mathrm{mg} / \mathrm{kg} / \mathrm{day}$ & $\begin{array}{l}\text { Twice to } \\
\text { three times } \\
\text { daily }\end{array}$ & $\begin{array}{l}16 \mathrm{mg} / \mathrm{kg} \\
\text { up to } 640 \mathrm{mg}\end{array}$ & No & No \\
\hline \multirow{3}{*}{$\begin{array}{l}\text { Calcium } \\
\text { channel } \\
\text { blockers }\end{array}$} & Amlodipine & $0.06 \mathrm{mg} / \mathrm{kg} / \mathrm{day}$ & Once daily & $\begin{array}{l}0.3 \mathrm{mg} / \mathrm{kg} \\
\text { up to } 10 \mathrm{mg}\end{array}$ & $>6$ y & No \\
\hline & Felodipine & $\begin{array}{l}2.5 \mathrm{mg} / \mathrm{day} \text { (no } \\
\text { dose referenced } \\
\text { to weight available) }\end{array}$ & Once daily & $10 \mathrm{mg}$ & No & No \\
\hline & $\begin{array}{l}\text { Extended- } \\
\text { release } \\
\text { nifedipine }\end{array}$ & $\begin{array}{l}0.25- \\
0.5 \mathrm{mg} / \mathrm{kg} / \text { day }\end{array}$ & $\begin{array}{l}\text { Once to } \\
\text { twice daily }\end{array}$ & $\begin{array}{l}3 \mathrm{mg} / \mathrm{kg} \\
\text { up to } 120 \mathrm{mg}\end{array}$ & No & No \\
\hline \multirow{5}{*}{$\begin{array}{l}\text { Angiotensin- } \\
\text { converting } \\
\text { enzyme } \\
\text { inhibitors }\end{array}$} & Captopril & $\begin{array}{l}0.3- \\
0.5 \mathrm{mg} / \mathrm{kg} / \mathrm{dose}\end{array}$ & $\begin{array}{l}\text { Twice to } \\
\text { three times } \\
\text { daily }\end{array}$ & $\begin{array}{l}6 \mathrm{~m} / \mathrm{kg} \\
\text { up to } 450 \mathrm{mg}\end{array}$ & No & No \\
\hline & Enalapril & $0.08 \mathrm{mg} / \mathrm{kg} / \mathrm{day}$ & Once daily & $\begin{array}{l}0.6 \mathrm{mg} / \mathrm{kg} \\
\text { up to } 40 \mathrm{mg}\end{array}$ & $>20 \mathrm{~kg}$ & No \\
\hline & Fosinopril & $0.1 \mathrm{mg} / \mathrm{kg} / \mathrm{day}$ & Once daily & $\begin{array}{l}0.6 \mathrm{mg} / \mathrm{kg} \\
\text { up to } 40 \mathrm{mg}\end{array}$ & No & No \\
\hline & Lisinopril & $0.08 \mathrm{mg} / \mathrm{kg} / \mathrm{day}$ & Once daily & $\begin{array}{l}0.6 \mathrm{mg} / \mathrm{kg} \\
\text { up to } 40 \mathrm{mg}\end{array}$ & $>20 \mathrm{~kg}$ & No \\
\hline & Ramipril & $\begin{array}{l}2.5- \\
6 \mathrm{mg} / \mathrm{day}\end{array}$ & Once daily & $20 \mathrm{mg}$ & No & No \\
\hline \multirow{4}{*}{$\begin{array}{l}\text { Angiotensin- } \\
\text { receptor } \\
\text { blockers }\end{array}$} & Candesartan & $\begin{array}{l}0.16- \\
0.5 \mathrm{mg} / \mathrm{kg} / \text { day }\end{array}$ & Once daily & $32 \mathrm{mg}$ & $>6 y$ & No \\
\hline & Irbesartan & $\begin{array}{l}75-150 \mathrm{mg} / \text { day } \\
\text { (no dose referenced } \\
\text { to weight available) }\end{array}$ & Once daily & $300 \mathrm{mg}$ & No & No \\
\hline & Losartan & $\begin{array}{l}0.75- \\
1.4 \mathrm{mg} / \mathrm{kg} / \text { day }\end{array}$ & Once daily & $\begin{array}{l}1.4 \mathrm{mg} / \mathrm{kg} \\
\text { up to } 100 \mathrm{mg}\end{array}$ & $>6 \mathrm{y}$ and $>20 \mathrm{~kg}$ & Yes \\
\hline & Valsartan & $1.3 \mathrm{mg} / \mathrm{kg} /$ day & Once daily & $\begin{array}{l}2.7 \mathrm{mg} / \mathrm{kg} \\
\text { up to } 150 \mathrm{mg}\end{array}$ & $>6 y$ & Yes \\
\hline
\end{tabular}

Note: ${ }^{\circ}$ Standard dose of chlortalidone has been decreased in adults because of side effects. Use in children should also be cautious with use of the lowest effective dose and monitoring of serum electrolytes. 
Beta-adrenergic blockers ( $B B S$ )

Beta-adrenergic antagonists reduce the effect of endogenous catecholamines on beta-adrenergic receptors. ${ }^{5}$ Although BBs were among the first and most widely used antihypertensive medications in children, there are limited studies evaluating BBs in children. ${ }^{5}$ Characteristics that distinguish one BB from another include cardioselectivity, alpha-adrenergic activity, hydrophilic and lipophilic properties and intrinsic sympathicomimetic activity. ${ }^{5}$ The variability of pharmacologic properties of drugs in this group and characteristics of each individual drug influence the selection of medication. ${ }^{5}$ There is limited information on efficacy and safety of the newer vasodilating betablockers like carvedilol (non-selective beta-blocker with alpha1-blocking property) and nebivolol (selective betal-blocker that has vasodilatory properties through the NO mechanism) for the treatment of hypertension in children. ${ }^{22}$

Possible side effects attributable to BBs include bradycardia, anorexia, asthma exacerbations, night terrors, heart block, fatigue, cold extremities, and sexual dysfunction. ${ }^{5}$ It is important to note that BBs are associated with changes in carbohydrate and lipid metabolism; and can inhibit the warning signs of hypoglycaemia. For patients with labile glycemic control, beta-adrenergic antagonists, including those that are cardioselective, should be avoided. ${ }^{21,23} \mathrm{BBs}$ are not considered first line therapy in adolescents because of their interference with physical activity.

Calcium channel blockers (CCBS)

Calcium channel blocking antihypertensives are a heterogeneous group of compounds that inhibit the influx of extracellular calcium into the cellular membrane of the smooth muscle and other contractile cells by blocking the transmembrane transport of calcium. This results in reduced contractility and arteriolar smooth muscle tone in a dose-dependent fashion. Dihydropyridines are the major class of CCBs used to treat essential hypertension in children because of their relative selectivity for arteriolar smooth muscle. ${ }^{5}$ These include amlodipine, isradipine, felodipine, nicardipine and nifedipine. They have shown efficacy in treating hypertension in children. Nicardipine and isradipine have been described to cause cerebral vasodilation and must be used cautiously in children with intracranial pathology if at all. ${ }^{24,25}$ On theoretical grounds this should be extended to all calcium channel blockers. ${ }^{24}$ The most common adverse effects reported with the use of CCBs include peripheral edema, dizziness, flushing, nausea, headache, and postural hypotension. Other reported adverse events include gingival hyperplasia, chest pain, nausea and vomiting, and reflex tachycardia seen with nifedipine. Side effects are seen more commonly as maximum dosages of the drugs are reached. ${ }^{5}$

The non-dihydropyridines are rarely used for the treatment of essential hypertension in children and adolescents because of their effects on cardiac conduction and contractility. ${ }^{5}$

\section{Angiotensin-converting enzym inhibitors}

ACEIs act on the renin-angiotensin system by preventing the conversion of angiotensin I to angiotensin II. Angiotensin II is a vasoconstrictor that also causes aldosterone secretion. ${ }^{5,21}$ In addition, ACEIs cause a decrease in bradykinin metabolism, which is thought to play also a role in the antihypertensive effects of these medications. ${ }^{21}$ ACEIs are widely used in the management of both primary and secondary hypertension in pediatric patients. In general, they have few adverse effects in standard doses and have convenient dosing schedules to improve adherence. ${ }^{5}$

The side effects of ACEIs in children do not differ from those seen in adults. They include hypotension, cough, hyperkalemia and elevated creatinine. ${ }^{5,21}$ Monitoring of serum electrolytes and creatinine are recommended with initiation of therapy and periodically to monitor the potassium and creatinine. Other adverse reactions include angioedema, headache, anemia, tachycardia, vertigo, dyspnea, rash and leucopenia. ${ }^{5}$ ACEIs are contraindicated during pregnancy and should be used cautiously in those of child-bearing age. ${ }^{21}$ Maternal use during pregnancy is associated with profound fetal hypotension, growth restriction, pulmonary and renal hypoplasia, anuria and neonatal death. ${ }^{5}$

\section{Angiotensin -II receptor blockers (ACEIS)}

ARBs act on the renin-angiotensin system by blocking the binding of angiotensin II to the AT1subtype of the angiotensin-II receptors in blood vessels and other tissues. Unlike ACEIs, ARBs have minimal effect on bradykinin metabolism. ${ }^{21}$ Data on the effects of ARBs in hypertensive children have accumulated recently. Several studies have demonstrated the efficacy of ARBs in the treatment of hypertension in children. The ARBs irbesartan, candesartan, valsartan, and losartan have shown to lower SBP and DBP. Irbesartan, candesartan and losartan have also shown to decrease proteinuria by over $50 \%$ as well. ARBs are generally well tolerated, with a favorable side effect profile. Side effects reported included rhinitis, urinary and gastrointestinal infections, headache, dizziness, blurred vision, fatigue, anemia and hyperkalemia. Other adverse reactions reported include rash and pruritus, hyperglyceridemia, leucopenia and thrombocytopenia. Although cough and angioedema occur in patients with ARBs, they are observed less frequently than in patients treated with ACEIs. 
The same precautions should be taken in pregnancy and in women of child-bearing age as with ACEIs. Similar congenital malformations seen with ACEI exposure during pregnancy have been reported. ${ }^{5}$

\section{Diuretics}

Diuretics are used primarily as a second medication when adequate BP has not been attained with monotherapy especially in adolescents and in children with renal disease with high volume states. There is a paucity of studies examining the use of diuretics for essential hypertension in children. The two types primarily used are thiazides and loop diuretics. Thiazide diuretics exert their effect on the distal tubule in the kidney to decrease sodium and water reabsorption and increase potassium secretion in an ion exchange mechanism by inhibiting the sodiumchloride membrane transporter. With long-term use, the thiazides produce vasodilation. Their efficacy is dependent on the glomerular filtration rate. They are most efficacious when the glomerular filtration rate (GFR) is $>50 \mathrm{ml} / \mathrm{min}$ and ineffective when the GFR is $<30 \mathrm{ml} / \mathrm{min}$. Thiazide diuretics produce elevations in blood glucose and insulin levels. Loop diuretics exert their effect at the ascending limb of the loop of Henle by decreasing the reabsorption of sodium and water by inhibiting the sodium-potassium-chloride membrane transporter. They also increase renal blood flow by reducing renovascular resistance. Loop diuretics are more potent than thiazides but their efficacy also decreases as GFR is reduced. ${ }^{5}$ They are used primarily in patients with underlying renal disease, fluid retention and renal insufficiency (30-50 ml/minute). ${ }^{1,21}$

Common side effects of diuretics relate to their effects on fluid and electrolyte balance, therefore serum electrolytes and creatinine should be monitored. Hypokalemia, volume contraction \pm hypotension, anorexia, nausea and vomiting, pancreatitis and elevated uric acid levels have been reported as well as ototoxicity with the use of loop diuretics. ${ }^{5}$

No clinical trials were found to support spironolactone's role in pediatric hypertension, although it is used in the treatment of hypertension secondary to diseases characterized by mineralocorticoid excess and as concomitant therapy in children taking medications that increase aldosterone secretion such as CCBs and vasodilators. ${ }^{21,23}$

\section{Other antihypertensive agents}

No pediatric studies have been conducted for direct vasodilators, centrally acting agents or alpha-1 receptor antagonists, despite their long history of clinical use in the pharmacological management of hypertension in children. ${ }^{1}$

\section{Long-term Follow-up}

As in adults, antihypertensive therapy in children and adolescents must be monitored closely, both for efficacy and for potential adverse effects. BP should be measured in the office every 2 to 4 weeks until good control is achieved. Once control is achieved, then office BP measurement every 3 to 4 months is appropriate. Periodic laboratory monitoring may also be required, particularly if a diuretic or agent affecting the reninangiotensin system is prescribed, or if the hypertensive child or adolescent has underlying renal disease as the cause of their hypertension. ${ }^{3}$ Since nocturnal and/or circadian rhythm of BP are probably directly correlated with long-term target damage, 24 hours BP measurement for monitoring is highly recommended. ${ }^{18}$

Adherence to treatment is an important long-term issue in the treatment of hypertension in children and adolescents, because most patients have so few symptoms. In adolescents, this situation is particularly difficult because they often do not like to take their medications and do not like to be perceived as different from their peers. If BP control can be achieved with a single drug that is taken once a day, this improves the likelihood of compliance and this should be taken into consideration when the initial agent is chosen. The adverse effect profile of the medication may also affect adherence. ${ }^{3}$

\section{Conclusion}

Although most of the adverse outcomes of hypertension occur in adulthood, there is now more clear recognition of the relationship between childhood and subsequent adult BP and identification of subclinical end-organ damage in children, adolescents, and adults. This should increase the focus by pediatricians and general practitioners on detection of hypertension and reinforce the efforts to achieve BP reduction via non-pharmacological and pharmacological treatments in children with hypertension.

\section{Acknowledgements}

Johan Vande Walle is currently primary investigator in the Novartis CVAL489K2306 trial. Pauline De Bruyne has received an independent grant for Strategic Basic Research of the Agency for Innovation by Science and Technology in Flanders (IWT).

\section{References}

1 Lurbe E, Cifkova R, Cruickshank JK, Dillon MJ, Ferreira I, Invitti $\mathrm{C}$, et al. Management of high blood pressure in children and adolescents: recommendations of the European Society of Hypertension. J Hypertens. 2009;27(9):1719-42.

2 Redwine KM, Acosta AA, Poffenbarger T, Portman RJ, Samuels J. Development of hypertension in adolescents with pre-hypertension. J Pediatr. 2012;160(1):98-103.

3 Kavey RE, Daniels SR, Flynn JT. Management of high blood pressure in children and adolescents. Cardiol Clin. 2010;28(4): 597-607.

4 Malatesta-Muncher R, Mitsnefes MM. Management of blood pressure in children. Curr Opin Nephrol Hypertens. 2012;21(3): 318-22.

5 Stephens MM, Fox BA, Maxwell L. Therapeutic options for the treatment of hypertension in children and adolescents. Clin Med Insights Circ Respir Pulm Med. 2012;6:13-25. 
6 National High Blood Pressure Education Program Working Group on High Blood Pressure in Children and Adolescents. The fourth report on the diagnosis, evaluation, and treatment of high blood pressure in children and adolescents. Pediatrics. 2004;114(2 Suppl 4th Report):555-76.

7 Brady TM, Fivush B, Parekh RS, Flynn JT. Racial differences among children with primary hypertension. Pediatrics. 2010;126(5):931-7.

8 Lurbe E. Reference blood pressure values in childhood: an issue to be solved. J Hypertens. 2012;30(10):1911-2.

9 Lurbe E, Torro MI, Alvarez J. Ambulatory blood pressure monitoring in children and adolescents: coming of age? Curr Hypertens Rep. 2013;15(3):143-9.

10 Seikaly MG. Highlights for the management of a child with hypertension. Int J Pediatr. 2012;2012:364716.

11 Rahiala E, Tikanoja T. Suspicion of aortic coarctation in an outpatient clinic: how should blood pressure measurements be performed? Clin Physiol. 2001;21(1):100-4.

12 Urbina E, Alpert B, Flynn J, Hayman L, Harshfield GA, Jacobson $\mathrm{M}$, et al. Ambulatory blood pressure monitoring in children and adolescents: recommendations for standard assessment: a scientific statement from the American Heart Association Atherosclerosis, Hypertension, and Obesity in Youth Committee of the council on cardiovascular disease in the young and the council for high blood pressure research. Hypertension. 2008;52(3):433-51.

13 Flynn JT, Daniels SR, Hayman LL, Maahs DM, McCrindle BW, Mitsnefes M, et al. Update: ambulatory blood pressure monitoring in children and adolescents: a scientific statement from the American Heart Association. Hypertension. 2014;63(5):1116-35.

14 Wuhl E, Witte K, Soergel M, Mehls O, Schaefer F, German Working Group on Pediatric H. Distribution of 24-h ambula- tory blood pressure in children: normalized reference values and role of body dimensions. J Hypertens. 2002;20(10):1995-2007.

15 Yang Q, Zhang Z, Kuklina EV, Fang J, Ayala C, Hong Y, et al. Sodium intake and blood pressure among US children and adolescents. Pediatrics. 2012; 130(4): 611-9.

16 Varda NM, Gregoric A. A diagnostic approach for the child with hypertension. Pediatr Nephrol. 2005;20(4):499-506.

17 Group ET, Wühl E, Trivelli A, Picca S, Litwin M, Peco-Antic A, et al. Strict blood-pressure control and progression of renal failure in children. N Engl J Med. 2009;361(17):1639-50.

18 Sharma AP, Mohammed J, Thomas B, Lansdell N, Norozi K, Filler G. Nighttime blood pressure, systolic blood pressure variability, and left ventricular mass index in children with hypertension. Pediatr Nephrol. 2013;28(8):1275-82.

19 Nguyen M, Mitsnefes M. Evaluation of hypertension by the general pediatrician. Curr Opin Pediatr. 2007;19(2):165-9.

20 Flynn JT, Daniels SR. Pharmacologic treatment of hypertension in children and adolescents. J Pediatr. 2006;149(6):746-54.

21 Meyers RS, Siu A. Pharmacotherapy review of chronic pediatric hypertension. Clin Ther. 2011;33(10):1331-56.

22 Cheng JW. Nebivolol: a third-generation beta-blocker for hypertension. Clin Ther. 2009;31(3):447-62.

23 Yaffe SJ, Aranda JV. Antihypertensive drugs. Neonatal and pediatric pharmacology therapeutic principles in practice. Fourth ed. Philadelphia, PA: Wolters Kuwer. Lippincott Williams \& Wilkins; 2011. p. 722-41.

24 Strauser LM, Groshong T, Tobias JD. Initial experience with isradipine for the treatment of hypertension in children. South Med J. 2000;93(3):287-93.

25 Blowey DL. Safety of the newer antihypertensive agents in children. Expert Opin Drug Saf. 2002;1(1):39-43.

26 Information TBCfP. Available from: www.bcfi.be. 